\title{
Covid-19 and the Opportunity for a Demographic Research Reset
}

Zeba Sathar

Population Council

Follow this and additional works at: https://knowledgecommons.popcouncil.org/series_pdr_essays-covid How does access to this work benefit you? Let us know!

\section{Recommended Citation}

Sathar, Zeba. "Covid-19 and the Opportunity for a Demographic Research Reset." In Covid-19 and the Global Demographic Research Agenda, edited by Landis MacKellar and Rachel Friedman, 64-67. New York: Population Council, 2021. 


\title{
Covid-19 and the Opportunity for a Demographic Research Reset
}

\author{
ZEBA SATHAR
}

THE COVID-19 PANDEMIC has unalterably changed the world. We are repeatedly told that things will never return to where they were and we must prepare to embrace the "new normal." For demographers, too, there is a need to remain relevant and responsive to the new realities. Many of us who have worked on analyzing mortality and fertility trends leading to the completion of the demographic transition may need to reexamine these trends in light of emerging new demographic norms and behaviors.

The year 2021 can be seen as an opportunity for demographic research to be bolder and for broadening the canvas of our work. It may be an opportune time to collaborate with other disciplines to tackle social policy, climate change, and political economy discourses where we have remained on the fringes. There is an opportunity for demographers to become more relevant and for the discipline to establish its centrality in the post-Covid world.

Several areas come to mind for the short-, medium-, and long-term demographic research agenda, both during and after the Covid-19 crisis. In the immediate term, during the Covid-19 peak period, demographers must join the study of the impact of the pandemic and be part of the solution, helping to tackle the pandemic, certainly in middle- and lower-income countries. Demographers can contribute to sharpening the policy response by helping to understand the spread and impact of the virus, and devise strategies for its containment. They can complement and strengthen epidemiological efforts by leveraging demographic tools and approaches for data collection and analysis. While epidemiologists provide data on the incidence of Covid cases, deaths, and positivity rates, demographers have expertise on population distributions and densities to estimate the spread and estimate who is most affected, how many are likely to get infected, and the impact in terms of changing death and birth rates.

In particular, it is important to lead on the challenge of how ongoing data collection can be used to build evidence concerning the pandemic. How can we use demographic surveillance better? Where can we be strategic and

Zeba Sathar, Population Council. 
piggyback additional questions onto ongoing surveys? And how can we create longitudinal panels to study long-term cross-generation effects?

A conventional demographic area where we can make immediate contributions is projections concerning the demographic effects of disruption in health services. In May 2020, when UNICEF projected that 29 million new babies would be born in the next nine months, the majority in South Asia, it was big news! However, it is the responsibility and domain of demographers to point out what is usual and what is unusual in the above example, to contextualize the number projected by UNICEF through comparison with the number that would have been born under normal scenarios. We should be ahead of the curve, predicting a rise in births due to higher conception rates due to lockdown or a rise in unwanted pregnancies due to the disruption in access to contraception services.

Another topic that has received much attention is how closing and disruption of regular outpatient departments and nonemergency services might increase risks of maternal and child deaths in particular. Demographers can certainly contribute to the accuracy of the health and mortality projections being used.

A more challenging and less conventional area of research will be for demographers to get involved in the crucial debates about the effect of lockdown in reducing death rates versus its cost for livelihoods during Covid. One of the major tensions across the world is when and whether to allow the full relaxation of shutdowns as the pandemic goes through its several waves and how this affects economic recovery. Currently, this is almost entirely the domain of economists, but we can certainly challenge some of the theories being promoted.

In political terms, a relaxation of lockdown is presented as a means to permit the working classes and the poor to eke out a living. But this is often being done at the potential cost of thousands of people being exposed to the infection and potentially thousands of preventable deaths. The perspective that shutdowns would have a huge economic cost in low-income countries that might far outweigh health benefits is illustrated in a study by two Yale researchers that caught the attention of those in the highest echelons of political discussions in South Asia. The other point of view, mainly spearheaded by public health and other less powerful groups, focuses on the dangers of lifting lockdowns and putting millions of voiceless, faceless workers outside their homes at high risk of death. Demographers have been largely absent from this discussion but need to contribute in assessing the probabilities and alternative projections of how many, if any, would die from the economic effects of the lockdown, as against those who would die by coming in contact with the Covid-19 infection.

Migration has not attracted as much attention as mortality and fertility. This will need to change as several of the major influences on population 
growth and distribution post Covid will be international migration flows. Several future scenarios of movement and displacements of populations have emerged as a result of the Covid pandemic In particular, international migration flows and streams are likely to be altered. Movement across borders will undoubtedly become more restricted. The crash in the travel industry, which epitomized the benefits of globalization and international connectedness, also bodes ill for international movement, including migration.

Demographers need to capture the new realities and gauge their economic-demographic consequences. Migration will affect livelihoods and compositions of populations in the recipient countries, including the United States, Europe, and the Middle East, which have relied on in-migration as an important component of labor supply and source of innovation. And for the sending countries in the low- and middle-income economies, remittancesoften the backbone of livelihoods-are likely to take a nosedive. An area even more neglected but of rising importance in contexts like India is internal migration. Once more, millions of internal migrants are likely to be affected as flows stall due to the concentration of the Covid-19 threat in urban centers.

Covid-19 will have other, related long-term effects on people's life trajectories, across the world. Living arrangements along with work are likely to change, with a direct bearing on familial and intergenerational relationships. Marriages and cohabitation may be delayed and ultimately childbearing will be affected by new ground rules about child-rearing and care of the elderly and sick. There is a potential scope for interdisciplinary research to examine these multilevel impacts of Covid-19.

Women's and girl's empowerment and gender relations and family responsibilities and roles, in particular, need to be revisited. Prior research in these important areas must be revived to study how shocks such as Covid-19 are likely to affect the lives and status of women and girls. Can we expect familial and gender relationships to be renegotiated in the long term? Is there a possibility of a recalibration of gender-related values and restrictions that may enable women and girls to gain autonomy and power?

As part of the reset, we demographers will do well to broaden our field to focus on class, regional, and other inequalities, and study social policy responses to rising threats and their implications. Through our strength as data-driven scientists, there is a chance to weigh in on important debates. We ought to join in the movement to improve the societies and world we live in. Post-Covid, there will be an opportunity to evaluate countries on the basis of whether they considered this challenge an opportunity to reassess public health systems, social safety nets, and social justice. The choice is between a society driven by the concentration of power and money for a few, or health and decent life for all, a society where every life counts.

Using this challenge of a reset of societal values as a premise or framework, we could start framing the task of building a more egalitarian society 
where there is no tolerance for inequalities. Given that many other scientists in realms such as history, economics, sociology, public health, and political science are also studying this pandemic and its social responses, we should ask: What is demography's comparative advantage and unique position? Demographers can research whether states that provide basic social services fared better in their response to Covid than others that abdicate the basic responsibility for health and education. We could contribute to the research on the impacts on the poorest and other excluded populations and how social safety nets can best be structured to ensure that these groups are able to sustain shocks such as Covid-19, now and in the future.

Demographers, working with other disciplines but retaining their niche with numbers and analytical tools like projections, can ensure that we are not just left with the hortatory language of the Sustainable Development Goals (SDGs). In practical terms, demographers are best equipped to give tangible shape to many of the interrelated SDGs. Environment and climate change are an important part of the SDGs and an emerging area is the intersection of climate change and vulnerability of the populations most exposed. Climate change research has been quite limited in incorporating the actual numbers and characteristics of those who are most vulnerable and whose lives and livelihoods will need adaptation, and are most likely to be directly affected. These are some of the interlinkages on which the new generation of demographers must lead.

Lastly, the reset for demographers beyond Covid-19 extends to questions about our normative assumptions about what the end of history (progress) in demographic transition looks like for fertility, mortality, and migration. Demographic transition theory is based on a progression of societies from high to low fertility and mortality. But what if these were not the natural end of demographic history? Can Covid-19 force us to rethink demographic theories? Could demographic transitions include waves of reverse migration, upturns in mortality, and increases in fertility in the face of Covid-like pandemics and diseases? The expectation of the new normal for demographers should entail both internal reflection and outward transformation of the field. 